\title{
REPETIBILIDADE DA PRODUÇÃO, NÚMERO E PESO DE FRUTO EM CIRIGUELEIRA (Spondias purpurea L.) ${ }^{1}$
}

\author{
JOSÉ SEVERINO DE LIRA JÚNIOR², JOÃO EMMANOEL FERNANDES BEZERRA \\ ROBERTO JOSÉ MELLO DE MOURA ${ }^{4}$, VENÉZIO FELIPE DOS SANTOS ${ }^{5}$
}

RESUMO - A repetibilidade permite estimar o número de avaliações ou ciclos produtivos para selecionar genótipos superiores com maior eficiência e menor custo operacional. Este trabalho estimou coeficientes de repetibilidade da produção, número e peso de fruto em 11 clones de cirigueleira, visando a avaliar a possibilidade de praticar seleção fenotípica individual. Foram analisados dados médios de 5 safras, oriundos de 3 plantas por clone, propagadas por estaquia. Os coeficientes foram estimados pelos métodos da análise de variância, componentes principais e análise estrutural. O método de componentes principais, baseados nas matrizes de variâncias e covariâncias, estima os maiores coeficientes em todas as características avaliadas. Com exceção do coeficiente estimado para número de frutos, pelo método de componentes principais, todos os outros atingiram valores iguais ou menores que 0,38 . De acordo com os resultados obtidos, é possível realizar seleção fenotípica individual entre os clones de cirigueleira avaliados, com base na produção e número de frutos por planta. As avaliações de $6 ; 4$ e 8 safras para produção, número e peso de frutos permitem selecionar clones promissores com cerca de $80 \%$ de acurácia. O clone IPA-6 produziu 17,62 kg de frutos/ planta, superando os demais materiais avaliados.

Termos para Indexação: Anacardiaceae, germoplasma, tropical, coeficiente, herdabilidade.

\section{REPEATABILITY OF THE PRODUCTION, NUMBER AND WEIGHT OF FRUIT IN RED MOMBIN (Spondias purpurea L.)}

\begin{abstract}
The repeatability allows estimating the number of evaluations or production cycles to select superior genotypes with higher efficiency and lower operating costs. This study estimated coefficient of repeatability of production, number and weight of fruit in 11 red mombin clones, to evaluate the possibility of performing individual phenotypic selection. Were analyzed average data of 5 seasons, from 3 plants per clone, propagated by cuttings. The coefficients were estimated by the methods of analysis of variance, principal components and structural analysis. The principal components method based on the variance and covariance matrices estimated the largest coefficients in all traits. Exception of the estimated coefficient for number of fruits, by the principal components method, all others reached values equal or smaller than 0.38 . It is possible to perform individual phenotypic selection between red mombin clones based on the production and number of fruit per plant. The evaluations of 6,4 and 8 harvests for production, number and weight of fruit allow to select clones with promising about $80 \%$ accuracy. The IPA- 6 clone produced $17.62 \mathrm{~kg}$ of fruits for plant, outperforming other materials evaluated.
\end{abstract}

Index terms: Anacardiaceae, germoplasm, tropical, coefficient, heritability .

\footnotetext{
'(Trabalho 294-13). Recebido em: 22-08-2013. Aceito para publicação em : 06-02-2014.

${ }^{2}$ Eng. Agr., D.Sc., Pesquisador do Instituto Agronômico de Pernambuco - IPA, Recife-PE. E-mail: lira.junior@ipa.br

${ }^{3}$ Eng. Agr., M.Sc., Pesquisador do Instituto Agronômico de Pernambuco - IPA, Recife-PE. E-mail: joao.emmanoel@ipa.br

${ }^{4}$ Eng. Agr., B.Sc., Pesquisador do Instituto Agronômico de Pernambuco - IPA, Itambé-PE. E-mail: roberto.moura@ipa.br

${ }^{5}$ Eng. Agr., B.Sc., Pesquisador do Instituto Agronômico de Pernambuco - IPA, Recife-PE. E-mail: venezio.felipe@ipa.br
} 


\section{INTRODUÇÃO}

A cirigueleira é uma fruteira tropical pertencente à família Anacardiaceae. Sua região de origem abrange parte do México e países da América Central (MILLER; SCHAAL, 2006). Encontra-se dispersa nos países da América Tropical (MACÍA; BARFOD, 2000), inclusive no Brasil, que concentra pomares extrativistas na região Nordeste. Apesar do elevado potencial econômico e grande aceitação do fruto para consumo in natura, a cirigueleira não dispõe de sistema de produção.

A safra da ciriguela no Nordeste brasileiro ocorre entre os meses de dezembro e fevereiro e concentra-se nas regiões semiáridas do Agreste e Sertão, e em menor proporção na Zona da Mata e Litoral. Durante esse período, são gerados vários empregos informais, desde a colheita do fruto até sua comercialização como fruta fresca nas Ceasas, feiras livres, supermercados e pontos de vendas em ruas e rodovias de acesso às grandes cidades do Nordeste (PINTO, 1997).

A planta pode atingir cerca de $7 \mathrm{~m}$ de altura, suas flores são perfeitas, e frutos são do tipo drupa elipsoidal, pesando em média $12 \mathrm{~g}$ (MARTINS et al., 2003). O endocarpo é súbero-lenhoso e estéril, ou seja, sem embrião. A polpa é doce, com aroma característico, podendo ser consumida ao natural, mas pode ser utilizada para preparar suco, doce, geleia, licor, sorvete e picolé (LIRA JÚNIOR et al., 2010).

O cultivo da cirigueleira necessita de clones selecionados com características agronômicas desejáveis, adaptados e fenotipicamente estáveis. Ao se selecionar um genótipo para cultivo comercial, espera-se que sua superioridade ou bom desempenho inicial se repita ao longo de seu ciclo de vida produtiva. Tal expectativa poderá ser confirmada a partir da estimativa de coeficientes de repetibilidade para as características de interesse agroindustrial.

A repetibilidade representa o valor máximo que a herdabilidade no sentido amplo pode atingir. Na prática, a repetibilidade permite estimar o número de avaliações ou ciclos produtivos para selecionar genótipos superiores com maior eficiência e menor custo operacional. É comum fazer medições repetidas num mesmo grupo de indivíduos de espécies perenes, principalmente em coleções ou bancos de germoplasma de fruteiras, implantados sem delineamento estatístico.

Atualmente, na literatura especializada, não há registros de trabalhos sobre repetibilidade em cirigueleira. Contudo, algumas espécies da família Anacardiaceae foram estudadas quanto à repetibilidade de características de produção e/ou do fruto de caju (CAVALCANTI et al., 2000), manga (COSTA, 2003), umbu (SANTOS, 1999) e cajá (SOARES et al., 2008; NUNES et al., 2011).

Este trabalho objetivou estimar coeficientes de repetibilidade em cirigueleira, por diferentes métodos, para as características produção por planta, número de frutos por planta e peso do fruto, e determinar o número mínimo de safras que devem ser avaliadas para praticar seleção fenotípica individual nas condições edafoclimáticas da Zona da Mata Norte de Pernambuco.

\section{MATERIAL E MÉTODOS}

O trabalho foi conduzido no banco de germoplasma de cirigueleira do Instituto Agronômico de Pernambuco (IPA), implantado em 1989 na Estação Experimental de Itambé. O município de Itambé situa-se no extremo Norte da Zona da Mata de Pernambuco, a $7^{\circ} 24^{\prime} 37^{\prime \prime}$ 'S e $35^{\circ} 06^{\prime} 46^{\prime \prime} \mathrm{O}$.. O clima é do tipo As' (Köppen), quente e úmido, com temperaturas entre 30 e $20^{\circ} \mathrm{C}$. A altitude é de 190 $\mathrm{m}$, com umidade relativa do ar em torno de $80 \%$. O índice pluvial médio anual é de aproximadamente $1.200 \mathrm{~mm}$. Cerca de $75 \%$ dessa precipitação é distribuída no período de março a agosto, e o restante, entre os meses de setembro e fevereiro.

$\mathrm{O}$ banco de germoplasma de cirigueleira do IPA contém atualmente 11 clones, sendo cada clone representado por 3 plantas, propagadas por estaquia, espaçadas em $7 \times 7 \mathrm{~m}$, sob condições de sequeiro. As estacas foram coletadas a partir de trabalhos de prospecção genética realizados nos Estados de Pernambuco, Paraíba e Rio Grande do Norte. As plantas foram conduzidas com adubações e podas de formação e de limpeza da copa. A produção teve início a partir no $2^{\circ}$ ano após o plantio, aumentando gradativamente nos anos subsequentes.

Foram avaliadas a produção, em kg de frutos planta ${ }^{-1}$, número de frutos por planta e o peso do fruto (g), referentes às colheitas de 1999, 2001, 2002, 2005 e 2006. As colheitas foram realizadas entre os meses de fevereiro e março de cada ano.

Os coeficientes de repetibilidade $(\hat{\mathrm{r}})$ foram estimados pelos seguintes métodos: a) Análise de variância (CRUZ et al., 2004), considerando o modelo estatístico a seguir, que possibilita remover os efeitos de ambiente temporário confundidos com a variação dentro de genótipos:

$Y_{i j}=\mu+g_{i}+a_{j}+\varepsilon_{i j}$, em que, $Y_{i j}=$ observação referente ao i-ésimo clone no j-ésimo ano; $\mu=$ média geral; $\mathrm{g}_{\mathrm{i}}=$ efeito do i-ésimo clone sob influência do ambiente permanente $(i=1,2 \ldots p) ; a_{j}=$ efeito fixo 
do ano na j-ésima medição $(j=1,2 \ldots n) ; \varepsilon_{i j}=$ erro experimental atribuído aos efeitos temporários do i-ésimo clone no j-ésimo ambiente. $\mathrm{O}$ estimador da variância genética $\left(\hat{\sigma}_{\mathrm{g}}{ }\right)$ foi dado por: $\hat{\sigma}_{\mathrm{g}}{ }_{\mathrm{g}}=$ QMG - QMR , em que: $\mathrm{QM} G$ = quadrado médio $\mathrm{ge}$

$\eta$

genótipo; $\mathrm{QMR}=$ quadrado médio do resíduo $=; \eta=$ número de anos avaliados. $\mathrm{O}$ estimador do coeficiente de repetibilidade $(\hat{\mathrm{r}})$ foi dado por: $\hat{\mathrm{r}}=\frac{\sigma_{\mathrm{g}}^{2}}{\sigma^{2}+\sigma^{2}} \mathrm{em}$ que: $\sigma^{2}{ }_{\mathrm{g}}=$ variância genética estimada; = variância residual estimada $=\mathrm{QMR}$; $\mathrm{b}$ ) componentes principais (ABEYWARDENA, 1972), com base na matriz $\Gamma$ de variâncias e covariâncias fenotípicas (CPcov). O estimador do coeficiente de repetibilidade $(\hat{\mathrm{r}})$ foi dado por: $: \hat{r}=\frac{\hat{\lambda}_{1}-\hat{\sigma}_{\hat{r}}^{2}}{\hat{\sigma}_{\hat{Y}}^{2}(\eta-1)}$,em que: $\hat{\lambda}_{1}=$ maior autovalor estimado, associado ao autovetor, cujos elementos têm o mesmo sinal e magnitudes semelhantes; ${ }^{2}{ }_{\mathrm{Y}}^{2}=$ componente de variância residual $\left(\sigma^{2}\right)+$ componente de variância genética $\left(\sigma_{\mathrm{g}}^{2}\right) ; \eta=$ número de anos avaliados; c) componentes principais (ABEYWARDENA, 1972), com base na matriz $\hat{R}$ de correlações fenotípicas (CPcor), entre cada par de medições avaliadas nos diferentes clones. O estimador do coeficiente de repetibilidade $(\hat{\mathrm{r}})$ foi dado por: $\hat{\mathrm{r}}=\frac{\left(\overrightarrow{\left.\lambda_{1}-1\right)}\right.}{\eta-1} \mathrm{em}$ que: $\lambda_{1}$ $=$ autovalor de $\mathrm{R}$ (matriz de correlação) estimado, associado ao autovetor, cujos elementos têm o mesmo sinal e magnitudes semelhantes; $\eta=$ número de anos avaliados; d) análise estrutural (MANSUR et al., 1981), baseada na matriz de correlações fenotípicas (AEcor) entre os clones em cada par de avaliação. O estimador do coeficiente de repetibilidade $(\hat{\mathrm{r}})$ foi dado por: $\frac{\alpha^{\prime} \hat{\mathrm{R}} \alpha-1}{\eta-1}$, em que: $\alpha_{1}=\left[\frac{\Gamma}{\sqrt{n}} \ldots \frac{\mathrm{T}}{\sqrt{n} n}\right]$ o autovetor com elementos paramétricos associados ao maior autovalor da matriz $\hat{\mathrm{R}} ; \eta=$ número de anos avaliados; e) análise estrutural (MANSUR et al., 1981), baseada na matriz $\hat{\Gamma}$ de variâncias e covariâncias fenotípicas (AEcov). $\mathrm{O}$ estimador do coeficiente de repetibilidade (r) foi

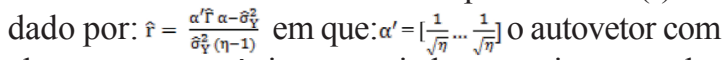
elementos paramétricos associados ao maior autovalor da matriz; componente de variância residual $\left(\sigma^{2}\right)+$ componente de variância genética $\left(\sigma_{\mathrm{g}}^{2}\right) ; \eta=$ número de anos avaliados.

O estimador do coeficiente de determinação genotípica $\left(\hat{\mathrm{R}}^{2}\right)$, que representa a porcentagem de certeza da predição do valor real dos clones, selecionados com base em $\eta$ medições, foi dado por: $\hat{R}^{2}=\frac{\eta \hat{r}}{1+\hat{r}(\eta-1)}$ em que: $\eta=$ número de medições; $\hat{\mathrm{r}}=$ coeficiente de repetibilidade estimado.

A partir da estimação dos coeficientes de repetibilidade $(\hat{r})$, por diferentes métodos, a predição do número de medições $\left(\eta_{0}\right)$, necessário para os níveis de precisão ou de determinação genotítpica $\left(\mathrm{R}^{2}\right)$ de 80; 85; 90; 95 e $99 \%$, na comparação $\hat{\eta}_{0}=\frac{\hat{\mathrm{R}}^{2}(1-\hat{\mathrm{r}})}{\left(1-\hat{\mathrm{R}}^{2}\right)}$ :s , foi calculado pela seguinte expressão:

As médias da produção por planta, número de frutos e o peso do fruto foram comparadas pelo teste Tukey, a 5\% de probabilidade.

Todas as análises estatísticas foram realizadas com o auxílio do programa GENES (Genética Quantitativa e Estatística Experimental) versão 2009.7.0.

\section{RESULTADOS E DISCUSSÃO}

O teste $F$ (Tabela 1) revelou que o efeito de clones foi significativo para produção e número de frutos. Esse resultado indica a possibilidade de sucesso na seleção fenotípica individual entre os clones de cirigueleira, avaliados sob as condições edafoclimáticas da Zona da Mata Norte de Pernambuco. Os coeficientes de variação (CVs) de $41,20 \%$, da produção por planta, e 39,91\%, do número de frutos, evidenciaram alta dispersão dos dados, em relação às respectivas médias de $10,84 \mathrm{~kg} /$ planta e 1.072,18 frutos. Esses CVs podem ter sido influenciados pela redução do índice pluvial nos anos de 1999 (39\%) e 2001 (33\%), considerando a média de $1.200 \mathrm{~mm} /$ ano.

O teste $\mathrm{F}$ não detectou diferença significativa, entre os clones para peso de fruto, cujo desviopadrão foi de 1,59 g e CVde 9,98 \%, mostrando uma pequena variação em torno da média geral de 10,16 $\mathrm{g}$ (Tabela 1).

A existência de variabilidade herdável para as características de interesse é condição essencial para o sucesso de qualquer programa de melhoramento genético. No caso da cirigueleira, assim como de outras espécies de propagação vegetativa, sabe-se que a estaquia não gera variabilidade e preserva a constituição genética da planta-matriz doadora de propágulos. Acredita-se que a variabilidade existente em cirigueleira seja devida à variabilidade natural, gerada em possíveis cruzamentos entre seus ancestrais e de eventuais mutações, ocorridas ao longo dos anos, e conservadas pela propagação vegetativa.

De acordo com Miller e Knouft (2006), os ancestrais da cirigueleira reproduzem-se sexuadamente e ocorrem de forma fragmentada nas florestas tropicais secas do México e da América Central. Miller e Schaal (2006) compararam amostras de DNA entre populações de cirigueleira cultivadas, propagadas vegetativamente, e populações selvagens da Mesoamérica, propagadas por semente. Os autores concluíram que a variação genética das populações cultivadas foi significativamente menor em relação às populações ancestrais. No entanto, a 
proporção da variação genética, distribuída entre populações cultivadas, foi maior do que entre populações selvagens. Esse resultado indica que é possível praticar seleção fenotípica individual em cirigueleira, cuja precisão e previsão de sucesso poderá ser estimada por coeficientes de repetibilidade das características de interesse agroindustrial.

Os coeficientes de repetibilidade estimados (Tabela 2) por componentes principais, com base nas matrizes de covariâncias (CPcov) e de correlações (CPcor), apresentaram os maiores valores, em relação àqueles estimados pela análise de variância (Anova) e análise estrutural, a partir das matrizes de variâncias e covariâncias (AEcov) e de correlações (AEcor).

A repetibilidade para produção variou de 0,43 a 0,49 com coeficientes de determinação em torno de $80 \%$ (Tabela 2). Esses resultados evidenciam uma razoável regularidade da produção de frutos, indicando um grau de dificuldade moderado para seleção fenotípica de clones superiores. As melhores perspectivas para selecionar os clones relativamente superiores, com níveis de confiabilidade entre 80 e $90 \%$, variaram de 4 a 9 safras, respectivamente (Tabela 3). Os ganhos em eficiência, acima de $90 \%$, aumentam consideravelmente o número de safras a serem avaliadas, tornando os trabalhos de seleção impraticáveis.

Para número de frutos, a repetibilidade variou de 0,47 a 0,58 com coeficientes de determinação de 81,75 a $87,48 \%$, respectivamente (Tabela 2 ). Esses resultados sinalizam que o caractere número de frutos apresenta regularidade média, com perspectiva moderada de sucesso na seleção fenotípica individual. A avaliação de 3 a 6 safras propicia níveis de confiança de 80 a $90 \%$, respectivamente (Tabela 3). Acima desses níveis, o número de avaliações cresce demasiadamente, tornando o processo seletivo muito demorado e, portanto, inexequível.

A repetibilidade para peso de fruto apresentou valores positivos, estimados apenas pelo método de componentes principais, com base nas matrizes de covariâncias $(0,29)$ e de correlações $(0,32)$, com níveis de confiabilidade de 67 e $71 \%$, respectivamente (Tabela 2 ). Esses resultados evidenciam maior dificuldade para selecionar clones superiores com base no peso de fruto, em função dos baixos coeficientes de repetibilidade e seus respectivos coeficientes de determinação. As avaliações de 8 a 19 safras estão associadas aos níveis de confiança de 80 a $90 \%$, respectivamente (Tabela 3).

Tanto pela análise de variância, quanto pela análise estrutural, foram estimadas repetibilidades com valores negativos para peso de fruto (Tabelas 2 e 3). Essas estimativas negativas ocorrem em função da não significância do efeito de genótipos (clones) e estimativas negativas da variância genética. Portanto, podemos interpretá-los como nulos ou sem repetibilidade.

Os intervalos para os coeficientes obtidos resultam em estimativas mais acuradas ou próximas de seus valores reais, justificando a utilização de vários métodos que permitem utilizar a repetibilidade com maior consistência.

Os coeficientes de repetibilidade atingiram valores menores em relação àqueles estimados para produção por planta, número de frutos e/ ou peso médio do fruto de algumas espécies da família Anacarciaceae, como cajueiro, mangueira, umbuzeiro e cajazeira. Cavalcanti et al. (2000) estimaram coeficientes de repetibilidade entre 0,51 (Anova) e 0,88 (CPcov) para produção de castanha em clones de cajueiro-anão-precoce, devendo-se realizar 3 medições com 95\% de confiança. Segundo Costa (2003), as características número total de frutos por planta e produção de frutos por planta apresentaram repetibilidades de 0,51 e 0,53 , sendo necessárias 9 e 8 medições para que sejam alcançados coeficientes de determinação superiores a $90 \%$, respectivamente. A estimativa de repetibilidade para peso médio do fruto foi de 0,81 , demonstrando alta regularidade de um ciclo para outro com bom controle genético. De acordo com Santos (1999), a repetibilidade variou de 0,68 a 0,76 para número de frutos por planta, de 0,87 a 0,89 para peso médio do fruto e de 0,65 a 0,75 para produção por planta. Três a quatro anos de medições serão necessários para o AF, NF e PW, e um ano para FW obter uma precisão de 90 \% para fornecer uma identificação fiável dos indivíduos para in situ ou conservação in situ. Soares et al. (2008) estimaram repetibilidade de 0,75 para peso do fruto de cajá, sendo necessárias 3 avaliações para atingir $90 \%$ de determinação do valor real dos genótipos avaliados. De acordo com Nunes et al. (2011), a repetibilidade estimada foi de 0,84 para massa do fruto.

A repetibilidade assume valores entre 0 e 1 , representando o limite superior que a herdabilidade no sentido amplo pode atingir. Para características quantitativas, como produção de frutos, controlados por vários genes e bastante influenciados pelo ambiente, geralmente os valores estimados de repetibilidade são baixos ou menores que 0,4 .

Caso a herdabilidade seja baixa, o valor fenotípico torna-se uma medida pouco confiável em relação ao valor genotípico, cuja superioridade relativa aparente poderá não ser devida a causa genética. Nesse caso, o aumento do número de 
avaliações, a minimização da influência ambiental e/ou a incorporação de maior variabilidade genética poderão resultar em aumento de precisão. Quando a repetibilidade é alta ou acima de 0,5 , indica que é possível predizer o valor real do indivíduo com um número relativamente pequeno de medições.

Verifica-se, na Tabela 4, que os clones de cirigueleira diferiram significativamente com relação à produção e número de frutos por planta. $\mathrm{O}$ clone IPA-6, que produziu $17,62 \mathrm{~kg}$ de frutos/planta, superou os clones IPA-11 e IPA-4, que produziram 6,23 e 5,96 kg de frutos/planta, respectivamente. Não foi detectada diferença significativa entre IPA-6 e os demais clones IPA-1; 2; 7; 8; 5;9; 3 e 10. Quanto ao número de frutos, o IPA-6 produziu, em média, 1.757 frutos e superou significativamente os clones IPA-11 e IPA-4, que produziram, em média, 605,4 e 600,4 frutos, respectivamente. Contudo, não houve diferença significativa entre os clones IPA-6 e IPA-1; 2; 7; 8; 5; 9 e 3 para número de frutos. Em relação ao peso do fruto, não foi detectada diferença significativa entre os clones avaliados.

A avaliação da diversidade genética desses clones de cirigueleira, e de outros materiais dispersos pela América Tropical, através de marcadores de DNA com associação aos dados de produção e à qualidade de fruto, fornecerá subsídios para melhor compreensão e à utilização deste recurso genético, bem como adotar estratégias mais precisas quanto ao descarte é introdução de novos clones, dentro de um contexto da seleção fenotípica individual, visando a explorar sua variabilidade natural.

TABELA 1- Resumo da análise de variância da produção de frutos (P), número de frutos (NF) e peso do fruto (PF) de 11 clones de cirigueleira (Spondias pupurea L.), pertencentes ao Instituto Agronômico de Pernambuco (IPA), Itambé-PE.

\begin{tabular}{lcccc}
\hline Fontes de variação & \multirow{2}{*}{ GL } & \multicolumn{3}{c}{ Quadrados médios } \\
\cline { 3 - 5 } & 4 & $\mathrm{P}$ & $\mathrm{NF}$ & $\mathrm{PF}$ \\
\hline Ambientes (anos) & 102,49 & $988.357,68$ & 22,70 \\
Genótipos (clones) & 10 & $94,76^{* *}$ & $1.003 .377,58^{* *}$ & $0,50^{\text {ns }}$ \\
Resíduo & 40 & 19,95 & $183.168,64$ & 1,03 \\
\hline Total & 54 & & & \\
\hline Média geral & & 10,84 (kg/planta) & $1.072,18$ (frutos/planta) & $10,16(\mathrm{~g})$ \\
CV (\%) & 41,21 & 39,92 & 9,98 \\
\hline
\end{tabular}

** = significativo pelo teste $\mathrm{F}(\mathrm{P}<0,01) ;$ - = valor negativo; $\mathrm{CV}=$ coeficiente de variação; $\mathrm{DP}=$ desvio-padrão

TABELA 2- Coeficientes de repetibilidade ( $(\uparrow)$ e seus respectivos coeficientes de determinação $(\mathbb{R})$ da produção de frutos (P), número de frutos (NF) e peso do fruto (PF) de 11 clones de cirigueleira (Spondias pupurea L.), pertencentes ao Instituto Agronômico (IPA), Itambé-PE.

\begin{tabular}{|c|c|c|c|c|c|c|}
\hline \multirow{2}{*}{ Métodos } & \multicolumn{2}{|c|}{$\overline{\mathbf{P}}$} & \multicolumn{2}{|c|}{$\mathrm{NF}$} & \multicolumn{2}{|c|}{ PF } \\
\hline & & $(\%)$ & & $(\%)$ & & $(\%)$ \\
\hline$\overline{\text { Anova }}$ & 0,43 & 78,94 & 0,47 & 81,75 & - & - \\
\hline CPcov & 0,49 & 83,32 & 0,58 & 87,48 & 0,32 & 71 \\
\hline CPcor & 0,44 & 79,93 & 0,49 & 82,72 & 0,29 & 67 \\
\hline AEcor & 0,43 & 79,26 & 0,48 & 82,33 & - & - \\
\hline AEcov & 0,43 & 78,94 & 0,47 & 81,75 & - & - \\
\hline
\end{tabular}

- = valores negativos; Anova = Análise de variância; $\mathrm{CPcov}=$ Componentes principais com base na matriz de variâncias e covariâncias; CPcor $=$ Componentes principais com base na matriz de correlações; AEcor = Análise estrutural com base na matriz de correlações; $\mathrm{AEcov}=$ Análise estrutural com base na matriz de variâncias e covariâncias.

TABELA 3- Números de safras associados $\left(\eta_{0}\right)$ aos diferentes coeficientes de determinação preestabelecidos $\left(\mathrm{R}^{2}\right)$ para produção de frutos $(\mathrm{P})$, número de frutos $(\mathrm{NF})$ e peso de fruto $(\mathrm{PF})$ de 11 clones de cirigueleira (Spondias pupurea L.) pertencentes ao Instituto Agronômico de Pernambuco (IPA), Itambé-PE.

\begin{tabular}{|c|c|c|c|c|c|c|c|c|c|c|c|c|}
\hline \multirow{2}{*}{$\mathrm{R}^{2}$} & \multicolumn{4}{|c|}{$P$} & \multicolumn{4}{|c|}{$\mathrm{NF}$} & \multicolumn{4}{|c|}{$\mathrm{PF}$} \\
\hline & Anova & CPcov & CPcor & AEcor & Anova & CPcov & CPcor & AEcor & Anova & CPcov & CPcor & AEcor \\
\hline 0,80 & 5 & 4 & 5 & 5 & 4 & 3 & 4 & 4 & - & 8 & 10 & - \\
\hline 0,85 & 8 & 6 & 7 & 7 & 6 & 4 & 6 & 6 & - & 12 & 14 & - \\
\hline 0,90 & 12 & 9 & 11 & 12 & 10 & 6 & 9 & 10 & - & 19 & 22 & - \\
\hline 0,95 & 25 & 19 & 24 & 25 & 21 & 14 & 20 & 20 & - & 40 & 46 & - \\
\hline 0,99 & 132 & 99 & 124 & 130 & 111 & 71 & 103 & 106 & - & 207 & 240 & - \\
\hline
\end{tabular}


TABELA 4- Médias de 5 anos da produção por planta, número de frutos e peso médio do fruto de 11 clones de cirigueleira (Spondias purpurea L.) do banco de germoplasma do Instituto Agronômico de Pernambuco (IPA), Itambé-PE.

\begin{tabular}{cccc}
\hline Clone & $\begin{array}{c}\text { Produção } \\
(\mathrm{kg} / \text { planta })\end{array}$ & $\begin{array}{c}\text { Número } \\
\text { de frutos }\end{array}$ & $\begin{array}{c}\text { Peso do fruto } \\
(\mathrm{g})\end{array}$ \\
\hline IPA-6 & $17,62 \mathrm{a}$ & $1.757,0 \mathrm{a}$ & $10,43 \mathrm{a}$ \\
IPA-1 & $15,05 \mathrm{ab}$ & $1.596,8 \mathrm{ab}$ & $9,66 \mathrm{a}$ \\
IPA-2 & $14,34 \mathrm{ab}$ & $1.442,8 \mathrm{abc}$ & $10,16 \mathrm{a}$ \\
IPA-7 & $13,80 \mathrm{ab}$ & $1.378,8 \mathrm{abc}$ & $10,06 \mathrm{a}$ \\
IPA-8 & $11,54 \mathrm{ab}$ & $1.106,6 \mathrm{abc}$ & $10,28 \mathrm{a}$ \\
IPA-5 & $10,86 \mathrm{ab}$ & $1.047,2 \mathrm{abc}$ & $10,48 \mathrm{a}$ \\
IPA-9 & $10,77 \mathrm{ab}$ & $995,2 \mathrm{abc}$ & $10,63 \mathrm{a}$ \\
IPA-3 & $8,82 \mathrm{ab}$ & $861,4 \mathrm{abc}$ & $9,68 \mathrm{a}$ \\
IPA-10 & $7,82 \mathrm{ab}$ & $739 \mathrm{bc}$ & $10,34 \mathrm{a}$ \\
IPA-11 & $6,23 \mathrm{~b}$ & $605,4 \mathrm{c}$ & $10,05 \mathrm{a}$ \\
IPA-4 & $5,96 \mathrm{~b}$ & $600,4 \mathrm{c}$ & $9,95 \mathrm{a}$ \\
\hline DMS & 9,97 & 966,92 & 2,18 \\
\hline
\end{tabular}

Médias seguidas pela mesma letra na coluna não diferem entre si, pelo teste de Tukey, a 5\% de probabilidade; DMS = diferença mínima significativa.

\section{CONCLUSÃO}

1-É possível realizar seleção fenotípica individual entre os clones de cirigueleira, com base nas características produção e número de frutos por planta. Os coeficientes estimados para peso de fruto são baixos e, portanto, não contribuem para discriminar os clones avaliados.

2-Os clones superiores podem ser selecionados a partir de 4 safras, com confiabilidade de $80 \%$, para produção, e $85 \%$, para número de frutos.

3-O clone IPA-6 apresenta o melhor desempenho médio, com 17,62 kg de frutos/planta e 1,757 frutos por planta. O peso do fruto apresenta pouca variação e atinge cerca de $10 \mathrm{~g}$ em todos os clones avaliados.

4-Os componentes principais, baseados nas matrizes de covariâncias e de correlações, estimaram os maiores coeficientes de repetibilidade.

\section{REFERÊNCIAS}

ABEYWARDENA, V. An application of principal components analysis in genetics. Journal of Genetics, Bangalore, v. 61, p. 27-51, 1972.

CAVALCANTI, J.J.V.; PAIVA, J.R.; BARROS, L.M.; CRISÓSTOMO, J.R.; CORREAA, M.P.F. Repetibilidade de caracteres de produção e porte da planta em clones de cajueiro-anão-precoce. Pesquisa Agropecuária Brasileira, Brasília, v. 35, n. 4, p. 773-777, 2000.

COSTA, J.G. Estimativas de repetibilidade de alguns caracteres de produção em mangueiras. Ciência Rural, Santa Maria, v. 33, n. 2, p. 263-266, 2003.

CRUZ, C.D.; REGAZZI, A.J.; CARNEIRO, P.C.S. Modelos biométricos aplicados ao melhoramento genético. Viçosa: Editora UFV, 2004. 480p.

LIRA JÚNIOR, J.S.; BEZERRA, J.E. F.; LEDERMAN, I.E.; ROBERTO, J.M.M. Produção e características físicoquímicas de clones de cirigueleira na Zona da Mata Norte de Pernambuco. Revista Brasileira de Ciências Agrárias, Recife, v. 5, n. 1, p.43-48, 2010. 
MACIA, M. J.; BARFOD, A.S. Economic botany of Spondias purpurea L. (Anacardiaceae) in Ecuador. Economic Botany, Saint Louis, v. 54, n.4, p. 449458. 2000.

MANSOUR, H.; NORDHEIN, E.V.; RUTLEDGE, J.J. Estimators of repeatability. Theoretical and Applied Genetics, Stuttgart, v.60, p.151-156, 1981.

MARTINS, L.P.; SILVA, S. de M.; ALVES, R.E.; FILGUEIRAS, H.A.C. Desenvolvimento de frutos de cirigueleira (Spondias purpúrea L.). Revista Brasileira de Fruticultura, Jaboticabal, v. 25, n. 1, p. 11-14, 2003.

MILLER, A. J.; SCHAAL, B.A. Domestication and the distribution of genetic variation in wild and cultivated populations of the Mesoamerican fruit tree Spondias purpurea L. (Anacardiaceae). Molecular Ecology, Vancouver, v. 15, p. 1467-1480, 2006.

MILlER, A. J.; KNOUFT, J.H. GIS-based characterization of the geographic distributions of wild and cultivated populations of the mesoamerican fruit tree Spondias purpurea (Anacardiaceae). American Journal of Botany, Saint Louis, v. 93, n. 12 , p. $1757-1767.2006$.
NUNES, J.A.R.; SANTANA, F.F.; GOMES, R.L.F.; LOPES, A.C.A.; PEREIRA, M.M.G.; SOARES, E.B. Stratified mass selection of promising Spondias mombin clones in a commercial crop. Crop Breeding and Applied Biotechnology, Londrina, v.11, p.141148, 2011.

PINTO, A.C.Q. Seriguela, fruta exótica com crescente valor no mercado. Informativo da Sociedade Brasileira de Fruticultura, Jaboticabal, v.16, n.3, p 23-24, 1997.

SANTOS, C.A.F. In situ evaluation of fruit yield and estimation of repeatability coefficient for major fruit traits of umbu tree [Spondias tuberosa (Anacardiaceae)] in the semi-arid region of Brazil. Genetic Resources and Crop Evolution, Drodrecht, v.46, p.455-460, 1999.

SOARES, E.B.; GOMES, R.L.F.; CAMPELO, J.E. G.; LOPES, A.C. de; MATOS FILHO, C.H.A. Repetibilidade e corrrelações entre caracteres morfoagronômicos de cajazeiras. Ciência Agrotécnica, Lavras, v. 32, n. 6, p. 1851-1857, 2008. 